\title{
OS IMPASSES DO FINANCIAMENTO FISCAL DO SUS
}

THE IMPASSES OF THE FISCAL FUNDING OF THE SUS

Sulamis Dain ${ }^{1}$

Resumo Este comentário inspira-se no artigo de Luciana Dias de Lima sobre as relações entre o federalismo fiscal e o processo de descentralização do Sistema Único de Saúde. Destaca e desdobra aspectos relativos às transformações no contexto das relações intergovernamentais e às mudanças na institucionalidade pública que marcam o período analisado pela autora. O comentário chama a atenção para o potencial de desconstrução das relações federativas do Sistema Único de Saúde descritas e analisadas no texto proposto para debate, se aprovado o novo projeto de reforma tributária do Executivo, em tramitação.

Palavras-chave financiamento público; federalismo e saúde; relações intergovernamentais; SUS.
Abstract This comment is inspired in the article written by Luciana Dias de Lima regarding the relationships between fiscal federalism and the process of decentralization of the Single Health System. It highlights and expands issues regarding the transformations that have taken place in the intergovernmental relationships and the changes in public institutionality that marked the period the author analyzed. The comment calls the reader's attention to the potential deconstruction of the federative relationships of the Single Health System described and analyzed in the text proposed for, if the Executive's new tax reform, which is currently proceduring, is approved. Keywords public funding; federalism and health, intergovernmental relationships; SUS. 


\section{Introdução}

O artigo "Federalismo fiscal e financiamento descentralizado do SUS: balanço de uma década expandida", de Luciana Dias de Lima, instiga à reflexão sobre os determinantes políticos e institucionais da atual configuração descentralizada do Sistema Único de Saúde (SUS), trazendo para a discussão a questão das relações intergovernamentais e da autonomia dos entes federativos frente à hierarquização de ações e serviços e dos critérios de descentralização próprios e essenciais à construção de um sistema único.

Ao chamar atenção para as restrições de natureza fiscal que afetam o financiamento do SUS, a autora remete o debate para os campos da política econômica e do ajuste fiscal brasileiro.

De fato, as mudanças no próprio campo das políticas de saúde têm sido fortemente influenciadas por reformas da seguridade, das relações federativas e pelas restrições no campo tributário. Desenham-se novos formatos institucionais no plano das relações intergovernamentais, bem como entre o governo e as organizações não-governamentais e, finalmente, entre o setor público e o setor privado. Diversificam-se as características do financiamento e provisão das políticas, tornando mais essenciais e complexas suas múltiplas dimensões, entre as quais a dimensão econômico-financeira.

O correto enquadramento da temática atual do financiamento à política de saúde requer também o aprendizado da transição entre um setor público centralizado, financiador direto e muitas vezes executor e um setor público capaz de delimitar e articular os recortes locais de materialização das políticas, capacitando-o também para a necessária catalisação dos recursos, nos níveis de governo pertinentes para a tarefa proposta.

Isto significa que, para viabilizar uma nova formulação de políticas e de estratégias de financiamento que apontem na direção da recuperação do investimento e do aperfeiçoamento da prestação de serviços prioritários na saúde, é preciso superar os conceitos convencionais de uma rígida divisão intergovernamental (encargos exclusivos a cada esfera de governo), intersetorial e entre o setor público e o setor privado. Esta é a nova realidade que se coloca como desafio à definição de novos padrões de financiamento e de novos parâmetros de avaliação econômico-financeira da política de saúde. Por esta razão, o artigo de Luciana Dias de Lima é muito oportuno e continua a tradição de análise federativa do financiamento da saúde. Vários autores têm estudado a questão federativa, destacando-se, entre outros, os estudos que associam o tema à descentralização da saúde (Dain, 2000; Faveret, 2003; Pastrana, 2003, Lima, 2007).

A política econômica, em suas dimensões macro e micro, e também o grau de compatibilização entre ambas afetam a formulação e implementação das políticas setoriais, e como tal devem ser levados em conta na análise a 
ser realizada. Assim como estes, o campo das relações intergovernamentais e a distribuição de receitas e de encargos por níveis de governo, particularmente nas estruturas federativas, tornam a rota de financiamento e provisão de serviços de saúde bastante complexa.

Este é o novo cenário para o estudo do financiamento da saúde. Para operacionalizá-lo, é necessário superar a abordagem tradicional do tema, indo além de discussões sobre coerência entre fontes e usos, ou sobre a natureza, equidade e suficiência de recursos, típicas da visão normativa vigente, e deslocar o debate para o campo das finanças públicas, ainda pouco explorado pelos que se dedicam ao planejamento das políticas de saúde.

É preciso conhecer a configuração concreta dos padrões de financiamento nacionais, sua estrutura tributária, a natureza e grau de autonomia das relações fiscais intergovernamentais.

De sistemas políticos unitários ou estruturas federativas dependerá o caráter (desconcentrado ou descentralizado) da receita pública e dos encargos de governo, bem como os desafios (menores ou maiores) em desenhar, do ponto de vista do financiamento, um sistema nacional de saúde.

De outra parte, a origem de seguro social ou de política universal, ou sua combinação, definirá o mix de recursos entre impostos e contribuições, eventualmente a natureza singular ou plural dos fundos de financiamento e a real possibilidade de configurar um sistema único de saúde ou, alternativamente, subsistemas, com lógicas, formas de gestão e clientelas diversas.

Finalmente, conhecendo a realidade dos países da América Latina e do Brasil, torna-se essencial relacionar a capacidade de financiamento setorial com os níveis de endividamento interno e externo, uma vez que as amortizações e encargos destas dívidas impõem restrições à livre disposição dos recursos gerados por impostos e contribuições sociais, recursos clássicos para o financiamento da saúde.

No Brasil, o manejo da política fiscal de curto prazo tem utilizado a elevação da carga tributária e o contingenciamento de recursos assim gerados para compor o superávit primário, utilizado para pagamento dos encargos da dívida pública. Assim, ao difícil processo de descentralização de recursos e encargos, típico de estruturas federativas, agrega-se uma competição por recursos, nas quais a política econômica tem sido priorizada em detrimento das políticas sociais de natureza universal, como saúde e educação. 


\section{À sombra do déficit público}

Na precisa formulação de Biasoto,

o déficit ganhou contornos de inimigo da sociedade e raiz de todos os problemas econômicos. A macroeconomia buscou um número síntese para incorporar aos modelos como a variável déficit público. No início dos anos 90, zerar o déficit passou a ser a senha para a credibilidade junto aos investidores internacionais (Biasoto, 1999, p. 5).

A adoção das políticas acima expostas colocou o espaço da política fiscal em discussão, dissociando crescentemente as ações para seu controle das verdadeiras causas do desequilíbrio das contas públicas. Diante da alegada crise fiscal do estado brasileiro, sabemos que as prioridades de alocação de recursos não refletem os desafios acima expostos.

Nunca pudemos evitar a priorização do pagamento dos encargos financeiros da dívida, seja ela interna ou externa. Nem que para isso os recursos fossem subtraídos da receita de contribuições sociais criadas para expandir os gastos universais e redistributivos da seguridade social.

Até o presente, persiste uma equivocada percepção de que as decisões constitucionais de 1988 foram responsáveis pelo crescimento do déficit na última década. A reforma tributária, por descentralizar receita para estados e municípios, sem a correspondente descentralização de encargos de governo, e a reforma previdenciária, por promover gastos adicionais com a proteção social, particularmente os de caráter universal, sem a necessária previsão de receita.

A conseqüência desta manipulação ideológica dos fatos conduz à priorização do pagamento de juros e ao corte e frustração recorrente dos gastos sociais, traduzindo uma hierarquização das decisões de gasto, pela qual o pagamento de juros é tido como inadiável.

Se pudéssemos alterar tais hierarquias e declarar inadiáveis os direitos sociais, não haveria dinheiro para pagar os juros. E a leitura da problemática do financiamento público seria construída de outra maneira, não mais em torno do caráter 'perdulário' do gasto fiscal, mas sim em torno do equívoco e da prepotência de uma política de juros que vem sacrificando o bom desempenho das contas públicas, endividando os brasileiros e comprometendo a capacidade de financiamento das políticas sociais, tudo isso em nome de uma estabilização fiscal nunca concretizada. 


\section{O federalismo fiscal entre o ajuste fiscal e o uso inadequado das contribuições sociais}

Durante os anos 2000, o gasto social como um todo explica apenas a metade do crescimento da carga tributária do governo federal, tendo sido a outra metade alocada ao superávit primário para fins de ajuste fiscal. Contrastando com o aumento de quase dois pontos percentuais da carga tributária alocado aos gastos com benefícios previdenciários durante o período, tanto os gastos em educação como em saúde permanecem quase constantes, com apropriação de apenas 0, 02\% do acréscimo de carga tributária na educação e de 0,03 \% na saúde, apesar da significativa elevação da carga de 4,37 pontos percentuais do PIB no período (Tabela 1).

Tabela 1

\begin{tabular}{lccccccc}
\hline \multicolumn{1}{l}{ Apropriação do aumento da carga tributária por programa } \\
\hline & $\mathbf{2 0 0 0}$ & $\mathbf{2 0 0 1}$ & $\mathbf{2 0 0 2}$ & $\mathbf{2 0 0 3}$ & $\mathbf{2 0 0 4}$ & $\mathbf{2 0 0 5}$ & $\mathbf{2 0 0 0 - 2 0 0 5}$ \\
\hline Vinculações universais (A) & 2,39 & 2,47 & 2,42 & 2,27 & 2,42 & 2,44 & 0,05 \\
Educação & 0,54 & 0,59 & 0,58 & 0,52 & 0,57 & 0,56 & 0,02 \\
Saúde & 1,85 & 1,87 & 1,84 & 1,75 & 1,85 & 1,88 & 0,03 \\
\hline Benefícios sociais (B) & 6,65 & 7,06 & 7,39 & 7,72 & 8,10 & 8,63 & 1,97 \\
Benefícios previdenciários & 5,97 & 6,28 & 6,54 & 6,88 & 7,12 & 7,54 & 1,56 \\
Seguro-desemprego & 0,50 & 0,55 & 0,59 & 0,55 & 0,56 & 0,61 & 0,12 \\
Assistência social & 0,18 & 0,22 & 0,26 & 0,29 & 0,42 & 0,48 & 0,30 \\
\hline =Soma (A+B) & 9,05 & 9,53 & 9,80 & 9,98 & 10,52 & 11,07 & 2,02 \\
Carga tributária federal & 22,25 & 23,52 & 25,04 & 24,23 & 25,10 & 26,62 & 4,37 \\
\hline
\end{tabular}

Fonte: Secretaria do Tesouro Nacional, Tribunal de Contas da União e Ministério da Saúde.

Nota: Elaborada por José Roberto Rodrigues Afonso.

Assim, no plano dos gastos federais, não cresceu a participação da saúde. Dito de outra maneira, o excedente de recursos extraído da seguridade social variou entre R\$12,4 bilhões, em 2001, e R \$26,5 bilhões, em 2005, até mesmo acima do limite de $20 \%$ legalmente autorizado pelo mecanismo da Desvinculação de Recursos da União (DRU). O superávit retirado da seguridade para fins de ajuste fiscal excedeu o gasto anual com saúde ao longo do período 2000 a 2005. De acordo com os dados abaixo, se nos últimos seis anos esse excedente tivesse sido investido no setor saúde, seus recursos teriam sido ampliados em mais de $100 \%$.

Ao centrar a análise nas possíveis fontes de financiamento da saúde, retiramos os tributos que já têm destinação exclusiva, como é o caso da receita previdenciária e do FGTS. Neste caso, a carga tributária 'disponível' da União seria de 16,52\%, em 2006, contra 14,35\%, em 2000.

No ano de 2006, as contribuições sociais criadas ou ampliadas para viabilização do orçamento da seguridade social são responsáveis por mais de 
$50 \%$ da arrecadação da União, ainda que excluídos os recursos da previdência e do FGTS. Além disso, entre 2000 e 2006, estas contribuições aumentaram em $2,46 \%$ sua participação no total $(48,45 \%$ em 2000 e 50,91\% em 2006), enquanto os impostos perderam participação praticamente na mesma proporção - 2,47\% (45,70\% em 2000 e 43,23\% em 2006).

De fato, a elevação da carga global (de 29\% do PIB, em 1998, para $35,9 \%$ do PIB, em 2006) repôs a participação federal na receita tributária disponível aos níveis dos anos 60. A participação dos municípios praticamente duplicou, em detrimento da representatividade dos estados no total da carga tributária disponível (Tabela 2).

Tabela 2

Relações fiscais intergovernamentais - 1965-2005

\begin{tabular}{lccccc}
\hline \multicolumn{7}{c}{ Divisão federativa da receita tributária disponível } \\
& $\begin{array}{c}\text { Carga } \\
\text { \% do PIB }\end{array}$ & União & Divisão federativa - \% total \\
& Estados & Municípios & Soma \\
\hline 1965 & 19,71 & 55,7 & 35,1 & 9,2 & 100,0 \\
1988 & 22,43 & 60,1 & 26,6 & 13,3 & 100,0 \\
2005 & 38,94 & 57,6 & 25,2 & 17,2 & 100,0 \\
\hline
\end{tabular}

Fonte: Afonso e Meirelles (2006).

Nota: Arrecadação própria mais/menos repartição constitucional de impostos.

Nos anos recentes, entre 2000 e 2005, apenas a receita disponível da União apresentou crescimento de 1,09\%, acompanhada da redução de $0,81 \%$ e $0,28 \%$ nas participações de estados e municípios, respectivamente.

Pode-se dizer que o modelo de descentralização de viés municipalista da saúde se reproduz no plano das relações fiscais intergovernamentais, transmitindo ao pacto federativo do SUS a fragilidade fiscal dos estados brasileiros e a corrosão de sua base vinculável, nos termos da emenda constitucional n 29 (EC 29).

\section{Fontes de financiamento da saúde nos anos 2000: relações intergovernamentais}

O artigo apresentado por Luciana Dias de Lima, bem como o conjunto de seus estudos no campo das relações federativas na saúde têm sido fundamentais para o esclarecimento dos limites e limitações ao financiamento do SUS na última década.

Estudo recente, de abrangência nacional (Dain; Lima; Pacheco, 2007), visou estabelecer as bases para a recuperação e expansão da receita do SUS, 
com impacto sobre as finanças da saúde, tanto no nível federal como em termos das relações intergovernamentais. Para tanto, foram analisadas: a composição das fontes no financiamento da saúde nos anos 2000/2007, assim como as mudanças recentes nas contribuições sociais e impostos que financiam a saúde e análise de sua produtividade fiscal.

Os trabalhos de Luciana Dias de Lima elucidam aspectos do atual sistema de partilha de receita, enfatizando:

- a falta de critérios endógenos às fórmulas adotadas no repasse que levem em consideração a distribuição irregular das bases tributárias, o que impede a diminuição das diferenças entre as receitas finais disponíveis nas esferas subnacionais de governo;

- a ausência de critérios pautados pelo esforço fiscal das esferas subnacionais, o que não permite estimular a arrecadação tributária e premiar o bom desempenho das máquinas fazendárias;

- a insuficiência de mecanismos que levem em conta as necessidades de recursos fiscais, o que dificulta a equalização da capacidade real de oferta de serviços públicos nessas instâncias, tendo em vista as diferenças de demandas e custos;

- a desintegração dos vários subsistemas que compõem a partilha fiscal, o que oblitera a análise integrada de seu impacto final sobre a capacidade de gasto dos entes subnacionais;

- a fragilidade das conexões orçamentárias entre os governos municipais e estaduais, o que determina um padrão federativo onde as articulações dominantes são aquelas entre o governo central e cada jurisdição municipal, induzindo à fragmentação e inviabilizando a superação das desigualdades.

Assim, fica claro que o problema do financiamento descentralizado do SUS vai além da instabilidade ou insuficiência de recursos e repousa mais bem na impotência dos gestores do SUS em impor soluções técnicas próprias frente a uma lógica de descentralização marcada por uma combinação de critérios cada vez mais incoerentes com a necessidade de garantir a equidade no acesso às ações e serviços de saúde em todo o território nacional.

A lógica própria do SUS é apenas um elemento (e não o mais importante) na construção pragmática das estruturas descentralizadas de financiamento público no Brasil, como bem demonstrado por Luciana Dias de Lima em seu artigo.

\section{Conclusão: o fantasma de uma nova reforma tributária e suas conseqüências para as relações intergovernamentais no SUS}

A título de contribuição para a reflexão, gostaria, entretanto, de trazer ao debate breves considerações sobre novas perspectivas de alteração do 
quadro federativo brasileiro, a partir do projeto de reforma tributária que ora tramita no Congresso Nacional. Em breves linhas, a reforma tributária propõe a alteração de receitas que são ou podem vir a ser vinculadas aos gastos com saúde, hoje instabilizados pela perda da CPMF.

Sem a CPMF, o novo IVA federal responderia pelo financiamento de $100 \%$ dos gastos com ações e serviços públicos de saúde. Se considerarmos as arrecadações tributárias dos últimos sete anos (2000 a 2006), podemos ter uma idéia da grandeza dos impostos e contribuições a serem alterados pela reforma tributária estrutural. Substituindo a Cofins, o PIS e a Cide pelo IVA federal e o ICMS pelo IVA estadual, vemos que o IVA Dual representaria grande parte da carga tributária nacional nos últimos cinco anos.

Destacando só as regras de partilha sugeridas no projeto de reforma encaminhado ao Congresso, e a partir dos impostos e contribuições que são sua base de cálculo, é possível estimar o montante de recursos do novo Fundo de Participação, dos quais 38,8\% financiariam a seguridade social como um todo, sem discriminação entre saúde, assistência social e previdência.

Segundo Delgado (2008), a nova vinculação tributária alocaria recursos à seguridade social e também ao financiamento do seguro desemprego. Além disso, a mudança afeta o dispositivo constitucional atual, que não limita em termos quantitativos o orçamento da seguridade, mas direciona a vinculação de várias contribuições sociais às despesas do sistema.

No novo arranjo, a vinculação tributária substitutiva, explicitamente colocada no novo texto constitucional, corresponde apenas a $37 \%$ do atual orçamento da seguridade social. Segundo o mesmo autor, "o restante ficaria, ao sabor das pressões da conjuntura, que se exercem na construção dos orçamentos anuais" (Delgado, 2008).

Portanto, a reforma tributária se afasta do SUS, contribuindo para seu desfinanciamento em termos de uma seguridade social enfraquecida. A partilha proposta não só não resolve como agrava a fragilidade das conexões orçamentárias entre os governos municipais e estaduais, o que determinaria um padrão federativo onde as articulações dominantes seriam aquelas entre o governo central e cada jurisdição municipal, induzindo à fragmentação e inviabilizando a superação das desigualdades.

Em conclusão, aplicar estes critérios para a partilha do SUS, além de revogar as virtudes do processo de descentralização atual, remete o Sistema de Saúde a critérios obsoletos, politizados no viés dos pequenos municípios e que desamparam as regiões metropolitanas onde se concentram $45 \%$ da população e para onde converge a pressão por serviços de saúde de média e alta complexidade.

Tais critérios ignoram as características de gestão do SUS, ameaçando profundamente o pacto federativo e a hierarquzação das ações baseados na própria lógica do sistema de saúde brasileiro. 


\section{Nota}

1 Professora titular da Universidade do Estado do Rio de Janeiro (Uerj). Doutora em Ciência Econômica pela Universidade Estadual de Campinas (Unicamp). Pós-doutora pela Universidade da Califórnia, Berkeley (UC). <sulamis@uol.com.br>

\section{Referências}

AFONSO, José Roberto R.; MEIRELLES, Beatriz Barbosa. Carga tributária global no Brasil, 2000/2005: cálculos revisitados?. NEPP Caderno, n. 61, Universidade Estadual de Campinas, Núcleo de Estudos de Políticas Públicas, mar. 2006.

BIASOTO, Geraldo. A polêmica sobre o déficit público brasileiro. Tese (Concurso Público de Títulos e Provas para Professor Adjunto) - Instituto de Economia (IE), Unicamp, Campinas, 1999.

DAIN, Sulamis. Do direito social à mercadoria. Tese defendida em 2000 (Concurso Público de Títulos e Provas para Professor Titular) - Instituto de Medicina Social, Universidade do Estado do Rio de Janeiro (IMS/Uerj), Rio de Janeiro, 2000.

O financiamento público na perspectiva da política social. Economia e Sociedade, v. 17, p. 113-140, 2001.

DAIN, Sulamis; LIMA, Luciana Dias de; PACHECO, Kleber. Alternativas para o financiamento público da saúde nos anos 2000. Diagnóstico do financiamento do MS aos governos subnacionais, Ministério da Saúde, 2007. Mimeografado.

DELGADO, Guilherme. Nota sobre a reforma tributária e suas implicações para os di- reitos sociais. Conferência Nacional dos Bispos do Brasil (CNBB), 2008.

FAVERET, Ana Cecília de Sá Campelo. Padrões de financiamento e descentralização na federação brasileira: saúde e educação fundamental nos anos 90. Tese (Doutorado em Saúde Coletiva). Instituto de Medicina Social, Universidade do Estado do Rio de Janeiro (IMS/Uerj), 2002.

A vinculação constitucional de recursos para a saúde: avanços, entraves e perspectivas. Ciência \& Saúde Coletiva, Rio de Janeiro, v. 8, n. 2, p. 371-378, 2003.

LIMA, Luciana Dias de. Conexões entre o federalismo fiscal e o financiamento da política de saúde no Brasil. Ciência \& Saúde Coletiva, v. 12, p. 511-522, 2007.

Federalismo, relações fiscais e financiamento do Sistema Único de Saúde: a distribuição de receitas vinculadas à saúde nos orçamentos municipais e estaduais. 1. ed. Rio de Janeiro: Museu da República, v. 1, 2007, 352 p.

PASTRANA, Rosa. A descentralização da política de saúde no Estado do Rio: uma avaliação da gestão plena do sistema municipal. Tese (Doutorado em Saúde Coletiva). Instituto de Medicina Social, Universidade do Estado do Rio de Janeiro, 2003. 
















